\title{
A comparative study on outcome of Type I Tympanoplasty using sliced 1-mm Conchal cartilage and full-thickness Conchal cartilage for grafting
}

\author{
Vijay Ramalingam ${ }^{1 *}$ (D), Kandasamy Kamindan ${ }^{1}$, Ram Karthik Murugan² and Velumani Rajeswari ${ }^{3}$
}

\begin{abstract}
Background: This study aims at comparing the pure tone audiogram and tympanogram results of a measured thickness $(1 \mathrm{~mm})$ conchal cartilage graft material (1.0-mm CC) with full-thickness conchal cartilage (FTCC) used for inactive chronic suppurative otitis media (CSOM) mucosal disease with moderate size perforation.

Results: A total of 40 successful cartilage tympanoplasty procedures were included in the prospective quasirandomised study. Patients aged between 15 and 55 years with inactive CSOM_moderate size perforation in the tympanic membrane were included. The patients were assessed at the end of 12 weeks with a pure tone audiogram and a tympanogram. The results were compared to know the compliance of the tympanic membrane (TM) between the two groups and the difference in audiometric gain (air-bone gap closure). The air-bone gap gain was better in the 1.0-mm CC group of patients (12) compared to the FTCC group of patients (7). The difference was statistically significant $(p=0.04)$. The $1.0-\mathrm{mm} \mathrm{CC}$ group of patients showed better compliance $(0.43)$ compared to FTCC group of patients (0.73). The air volume and compliance were significantly better in the 1-mm CC group compared to the FTCC group ( $p=0.031$ and 0.01 respectively).

Conclusion: The use of sliced cartilage seems to have a better role in reconstructing the TM when compared to full-thickness cartilage as graft material. It is indeed beneficial to have a compliant TM. Though the results cannot be compared with temporalis fascia grafts, the use of 1.0-mm CC has its advantage in producing an audio logically acceptable outcome in tympanoplasty surgery.
\end{abstract}

\section{Background}

The primary objective of doing a tympanoplasty is to reconstruct the diseased tympanic membrane with central perforation in chronic suppurative otitis media (CSOM). A successful outcome is determined by an intact, mobile tympanic membrane with good hearing. The graft materials used for the procedure were skin graft, fascia lata, fascia temporalis, vein and cartilage. The cartilages that were used are usually harvested from the pinna. In the pinna, it is usually from the conchal bowl. The thickness of the conchal cartilage differs from the site of harvesting $[1,2]$. It is documented in certain studies that the use of full-thickness cartilage reduces the compliance of the tympanic membrane (TM) [3, 4]. We conducted this study comparing the hearing results and compliance of the tympanic membrane between the sliced conchal cartilage (1.0-mm CC) and full-thickness conchal cartilage (FTCC) used in successful tympanoplasty procedures. The aim of the study is to know the difference in compliance and assess the audio logic gain between the two groups.

\footnotetext{
* Correspondence: revjram@gmail.com

${ }^{1} \mathrm{KMCH}$ Institute of Health Sciences and Research, Coimbatore, India

Full list of author information is available at the end of the article
}

\section{Springer Open}

(๑) The Author(s). 2020 Open Access This article is licensed under a Creative Commons Attribution 4.0 International License, which permits use, sharing, adaptation, distribution and reproduction in any medium or format, as long as you give appropriate credit to the original author(s) and the source, provide a link to the Creative Commons licence, and indicate if changes were made. The images or other third party material in this article are included in the article's Creative Commons licence, unless indicated otherwise in a credit line to the material. If material is not included in the article's Creative Commons licence and your intended use is not permitted by statutory regulation or exceeds the permitted use, you will need to obtain permission directly from the copyright holder. To view a copy of this licence, visit http://creativecommons.org/licenses/by/4.0/. 


\section{Methods}

We conducted the study in the Department of Otorhinolaryngology and Audiology of our institution after obtaining permission from the Institutional Human Ethics Committee from January 2015 to July 2017. A total of 40 tympanoplasty ears were enrolled in the study by quasirandomisation. They were divided into two groups. Twenty ears with successful tympanoplasty using sliced cartilage of $1 \mathrm{~mm}$ thickness were enrolled in one group (odd), and 20 ears enrolled in the other group underwent successful fullthickness cartilage tympanoplasty (even). The total number of patients in the study was 32. Some of the patients had bilateral disease.

All patients between the age of 15 and 55 years having inactive CSOM: moderate size TM perforation who underwent successful tympanoplasty with cartilage (1$\mathrm{mm}$ CC and FTCC) were included in the study (Fig. 1). Patients who were $<15$ years and $>55$ years, who had ear discharge in the last 12 weeks, who had subtotal/total TM perforation, who had attic perforation with or without cholesteatoma, with mixed hearing loss or sensorineural hearing loss, with sclerosed or partially sclerosed mastoid (compared to opposite ear in unilateral perforation), had a previous history of ear surgery were excluded from the study.

Every patient included in the study who was taken up for tympanoplasty was subjected to examination under the microscope, preoperative pure tone audiometry, Xray of both mastoids and preoperative anaesthetic screening before doing the procedure. The same steps in the procedure were followed for all of the patients.

The procedure was done under general anaesthesia (GA). Local anaesthesia of 1:1,00,000 adrenaline given in the four quadrants of the external auditory canal for all patients.

Post-aural Wilde's incision was made. Periosteum incised and elevated from the temporal bone cortex.
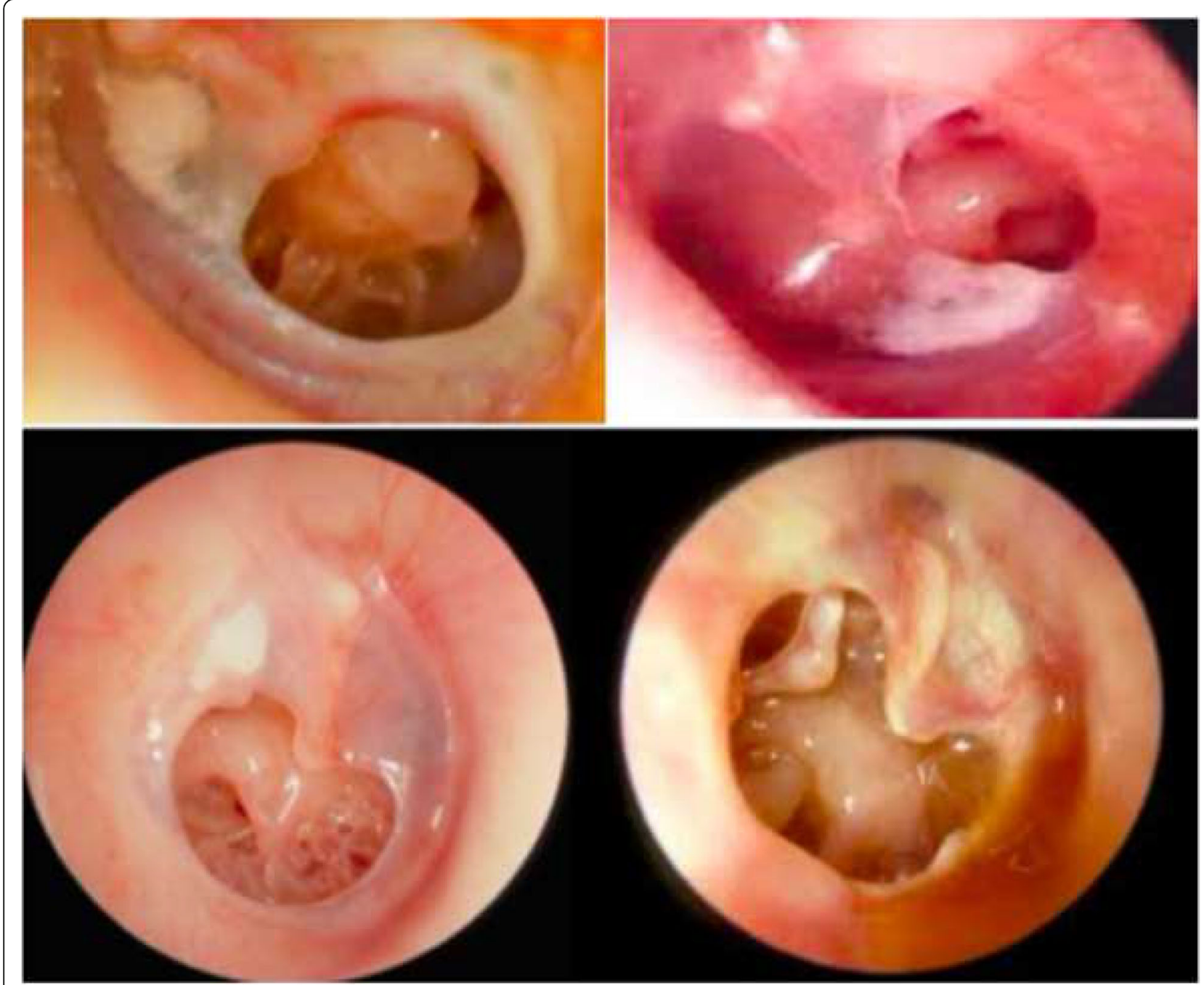

Fig. 1 Showing the TM perforations 
Posterior meatotomy was made and external auditory canal along with the tympanic membrane with its perforation was visualised. Ear canal packed with cottonoids soaked in local anaesthetic (4\% lidocaine) and adrenaline for local vasoconstriction.

The margins of the perforation were freshened by using a sickle knife, and under the surface of the remnant tympanic membrane was made raw with a round knife. Rosen incision from 6'o clock position to 1'o clock position anterior to the lateral process of malleus was made and the tympanomeatal flap was elevated, annulus was lifted from the sulcus and the middle ear was entered, the malleus was skeletonised from the lateral process to tip. The ossicular continuity confirmed by demonstrating a round window reflex.

Conchal cartilage was harvested from the conchal bowl (Fig. 2). The thickness was measured with callipers. For patient's ear in the 1-mm CC group, cartilage slicer device (Dr. Khan's SLICE!T) was used to slice the cartilage to $1 \mathrm{~mm}$ thickness (Fig. 3). The perichondrium on one side of the cartilage was retained and cartilage was kept as an underlay graft with the perichondrium facing the external auditory canal. The tympanomeatal flap was repositioned. The external auditory canal was packed with medicated gel foam. Standard postoperative mastoid dressing and care was carried out for all the patients.

Postoperatively, all the patients were given weight calculated intravenous cefotaxime for 3 days. All the patients were discharged on the fourth postoperative day. They were followed up weekly for the first month and biweekly for the next 2 months. On each visit, the healing of the tympanic membrane was documented. On the 12th postoperative week, all the patients were subjected to pure tone audiogram and tympanogram $(226,678,100$ $\mathrm{Hz}$ ). If the patient had a residual or reperforation at the end of 12 weeks, they were excluded from the study.

The results were tabulated and analysed. PASW ver. 18.0 was adopted for statistical study. Distribution of the variables was verified with the Kolmogorov-Smirnov test.

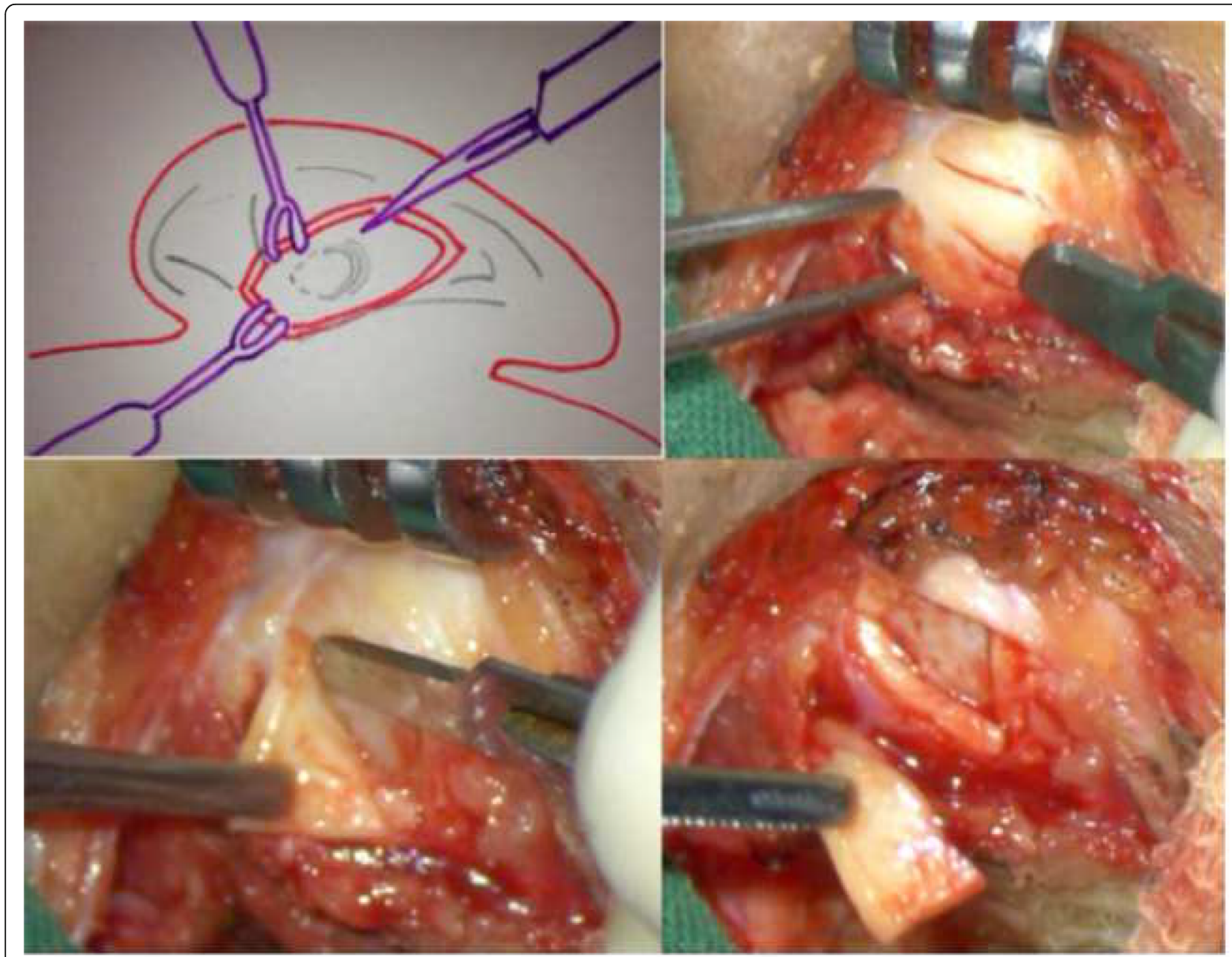

Fig. 2 Showing the method of harvesting the conchal cartilage 


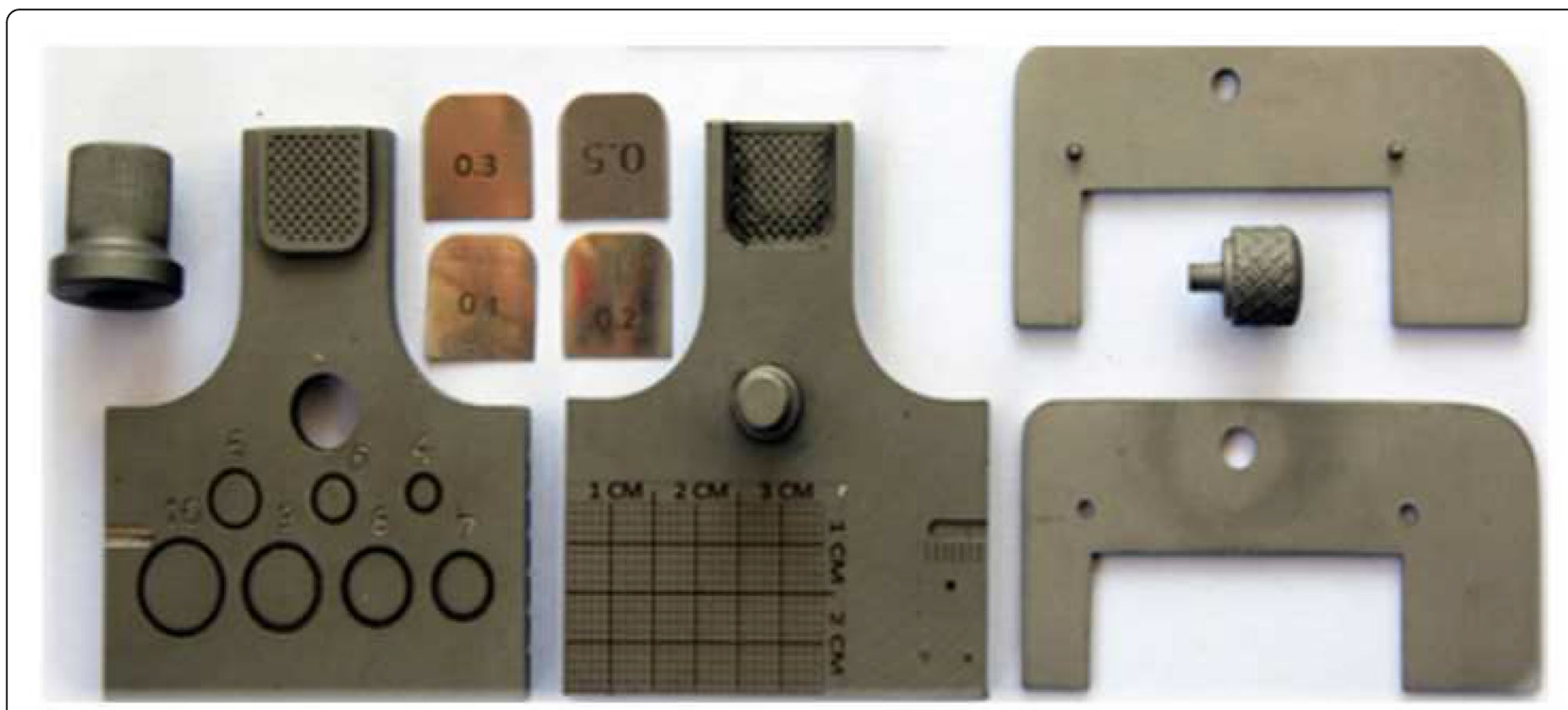

Fig. 3 Showing the image of Dr. Khan's SLICE!T cartilage slicer used for slicing the conchal cartilage

Independent sample $t$ test and Mann-Whitney $U$ test were used in the quantitative data analysis. Chi-square test was used to analyse qualitative data. $p$ values $<0.05$ were documented as statistically significant.

\section{Results}

Of the 40 ears for which tympanoplasty was done (32 patients), 18 patients were male and 14 were female. The mean age of the patients was $\sim 32$ years. Twenty ears were operated with sliced conchal cartilage (1-mm $\mathrm{CC}$ ) and 20 ears underwent tympanoplasty with full thickness conchal cartilage (FTCC). The age and sex distribution were not statistically significant in the two groups.

In the $1-\mathrm{mm} \mathrm{CC}$ group, the mean preoperative airbone gap (ABG) was $29 \mathrm{~dB}$, and the postoperative ABG was $17 \mathrm{~dB}$. The $\mathrm{ABG}$ gain was $12 \mathrm{~dB}$ in $1-\mathrm{mm} \mathrm{CC}$ group. There was a statistically significant audiological gain $(p=0.03)$ (Table 1, Fig. 4).
In the FTCC group, the mean preoperative ABG was $28 \mathrm{~dB}$, and the postoperative ABG was $21 \mathrm{~dB}$. The ABG gain was $7 \mathrm{~dB}$. The improvement was not statistically significant $(p=0.4)$. Between the two groups, the mean ABG gain was statistically significant $(p=0.04)$.

Tympanograms were done measuring the volume, pressure and compliance between the two groups postoperatively at $226 \mathrm{~Hz}, 678 \mathrm{~Hz}$ and $1000 \mathrm{~Hz}$. The compliance value at $226 \mathrm{~Hz}$ in the $1-\mathrm{mm} \mathrm{CC}$ group was 0.43 when compared to the FTCC group in which it was 0.73 . Also, the volume of air in the $1-\mathrm{mm} \mathrm{CC}$ group at $226 \mathrm{~Hz}$ was 2.5 when compared to 1.75 in FTCC group. The data was statistically significant $(p=0.01$ and 0.031 respectively). At all other frequencies, the difference was not statistically significant (Table 2, Fig. 5).

\section{Discussion}

When temporalis fascia is compared with cartilage, muscle fascia has the advantages of easily moldability and a structure that ensembles tympanic membrane [5].

Table 1 Preoperative and postoperative pure tone audiogam

\begin{tabular}{|l|l|l|l|}
\hline & $1 \mathrm{~mm} \mathrm{CC}$ & FT CC & Gain ( p value) \\
\hline ABG & & & \\
Pre-operative & $29 \mathrm{~dB}$ & $28 \mathrm{~dB}$ & - \\
Post-operative & $17 \mathrm{~dB}$ & $21 \mathrm{~dB}$ & - \\
Gain & $12 \mathrm{~dB}$ & $7 \mathrm{~dB}$ & 0.04 \\
P value & 0.03 & 0.4 & - \\
\hline
\end{tabular}




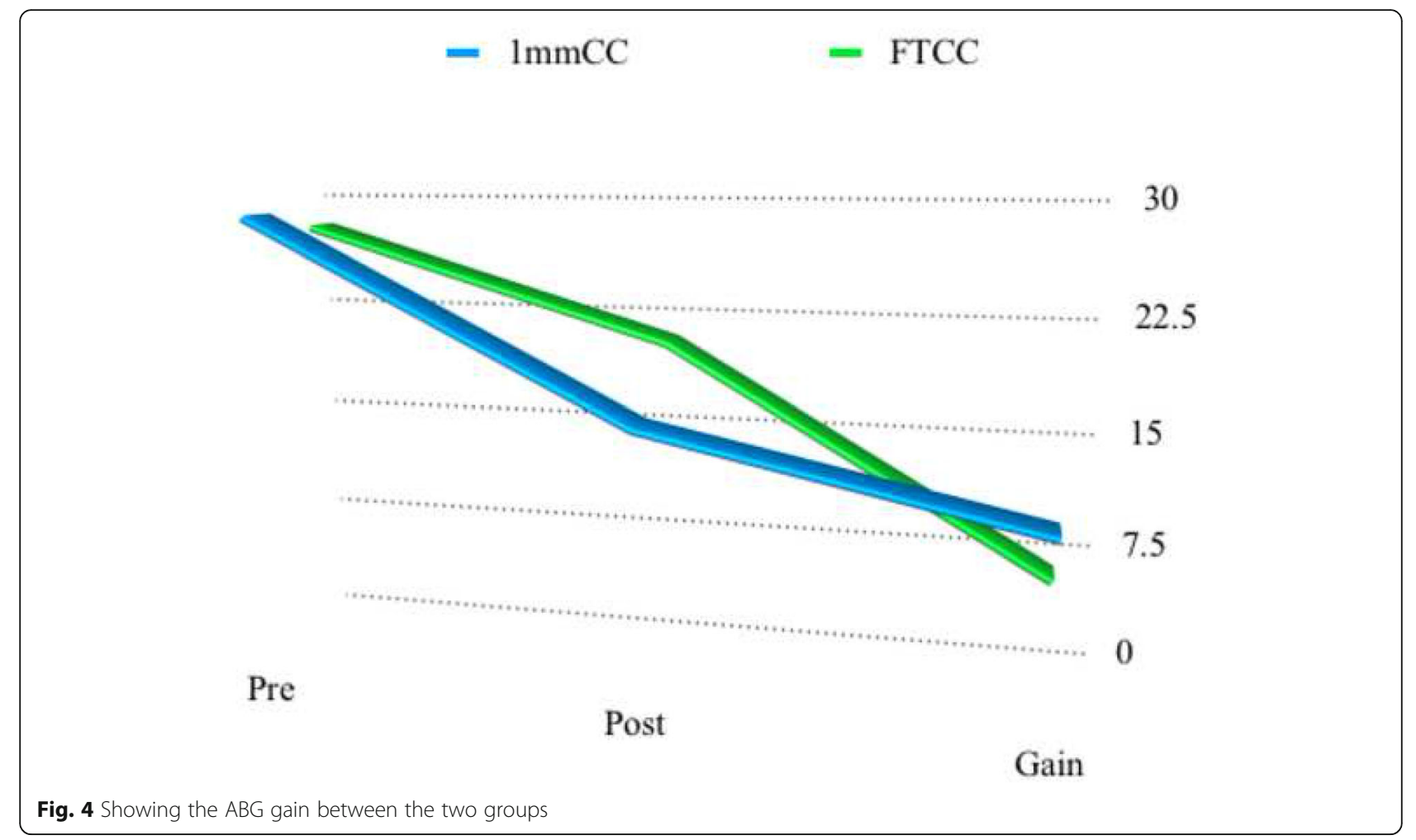

Some studies have documented a drop in graft performance as age goes by $[6,7]$. This is why we need thick and strong cartilage material as an alternative [8-10]. And because it is thicker than a fascia, it does not undergo atrophy $[11,12]$. The shape of the cartilage can be altered for appropriate placement of the graft by underlay technique and that adds to the advantage $[13,14]$. The greatest concern now is the thickness of the graft material that is used for reconstruction. Many studies documented the reduction in ABG closure and reduction in the compliance of the TM in the long run [15-17]. All these studies compare cartilage with fascia. We have compared the results by reducing the thickness of the cartilage to $1 \mathrm{~mm}$ with the help of a cartilage slicer that gives a tailored thickness of cartilage that can be precisely used in appropriate conditions. The mean ABG closure is comparable to the study conducted by Kirazli et al. [18]. Our study conducted using a 1-mm CC gave an ABG closure of $12 \mathrm{~dB}$.

Moore et al. did revision tympanoplasties using conchal cartilage from the conchal bowl [5]. These cartilages resist retraction and help in creating appropriate middle ear volume. Our study showed a statistical difference in $226 \mathrm{~Hz}$ tympanograms where 1-mm CC group showed better compliance when compared to FT CC graft materials. The results were comparable to one study conducted by Greek et al. [7]. Although higher frequencies show better comparison, our study did not show any statistical difference for higher frequencies.

Table 2 Showing the difference in air volume and compliance between two groups

\begin{tabular}{|l|l|l|l|l|}
\hline & & $1 \mathrm{mmCC}$ & FTCC & p value \\
\hline Air Volume & $226 \mathrm{~Hz}$ & 2.5 & 1.75 & 0.031 \\
& $678 \mathrm{~Hz}$ & 2.2 & 1.9 & 0.4 \\
& $1 \mathrm{~K} \mathrm{HZ}$ & 1.9 & 2.0 & 0.6 \\
\hline Compliance & $226 \mathrm{~Hz}$ & 0.43 & 0.73 & 0.01 \\
& $678 \mathrm{~Hz}$ & 0.65 & 0.71 & 0.40 \\
& $1 \mathrm{~K} \mathrm{HZ}$ & 0.68 & 0.77 & 0.62 \\
\hline
\end{tabular}




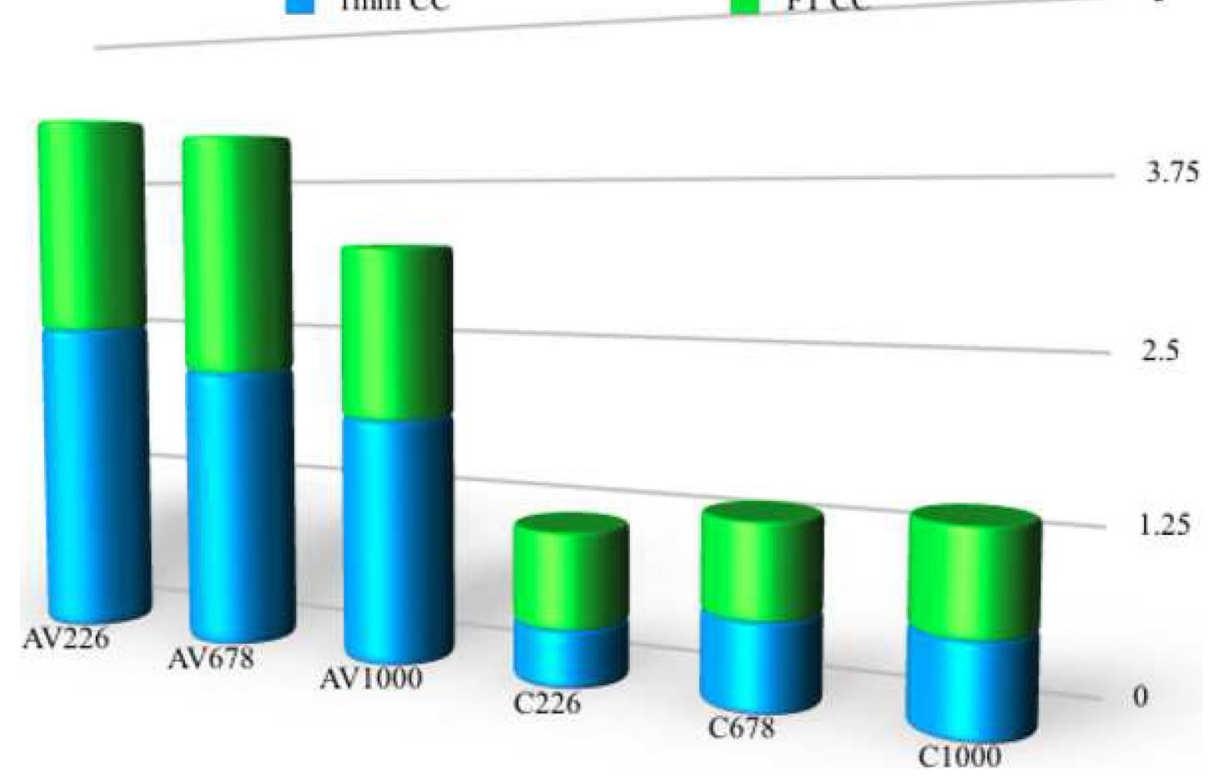

Fig. 5 Showing the tympanogram values containing air volume (AV) and compliance values (C)

\section{Conclusion}

Our study found evidence of a difference in ABG closure between the two groups. The 1-mm CC group had better ABG closure than the FTCC group and hence a good gain in hearing. The tympanogram results showed improved compliance in the $1-\mathrm{mm} \mathrm{CC}$ group when compared to the FTCC group. This study explains the need to use sliced cartilage of $1 \mathrm{~mm}$ thickness or less in case of first-time tympanoplasty. A long-term randomised prospective controlled study may be needed for understanding the healing process.

\section{Limitations}

Long-term follow-up of the healed tympanic membrane

\section{Abbreviations}

CSOM: Chronic suppurative otitis media; TM: Tympanic membrane; 0-mm

CC: 1.0-mm conchal cartilage; FTCC: Full-thickness conchal cartilage;

PTA: Pure tone audiogram; ABG: Air-bone gap

\section{Acknowledgements}

Not applicable

\section{Authors' contributions}

VR is the first author, corresponding, principal investigator and surgeon in charge; KK is the second author, assistant surgeon and data collection in charge for study; RM is the audiologist and speech pathologist and RV is the statistician, data interpretation, and outcome analyst. All the above have participated in the study with satisfactory accomplishment of their roles. All authors read and approved the final manuscript.

\section{Funding}

There was no funding required for the conduct of the study.

\section{Availability of data and materials}

The datasets used and/or analysed during the current study are available from the corresponding author on reasonable request.

\section{Ethics approval and consent to participate}

The ethical committee clearance was obtained in the month of December 2018 from The Institutional Human Ethics Committee (DCGl Reg. no. ECR/ 668/INST/TN/2014) with reference no. IHEC/136/ENT/1416. A consent for willingness to participate in the study was obtained from the patients before the start of the study.

\section{Consent for publication}

Not applicable

\section{Competing interests}

There were no competing interests in the study design.

\section{Author details}

${ }^{1} \mathrm{KMCH}$ Institute of Health Sciences and Research, Coimbatore, India. ${ }^{2} \mathrm{TN}$ MGR University, Chennai, India. ${ }^{3}$ IPMER, Pondicherry, India.

Received: 18 March 2020 Accepted: 14 May 2020

Published online: 08 July 2020

\section{References}

1. Dornhoffer $\lrcorner$ (1997) Hearing results with cartilage tympanoplasty. Laryngoscope v 107:1094-1099

2. $\quad$ Dornhoffer JL (2006) Cartilage tympanoplasty. Otolaryngol Clin N Am 39: 1161-1176

3. Hunter LL, Margolis RH (1992) Multifrequency tympanometry: current clinical application. Ann J Audiol 1:33-43

4. Valvik BR, Johnsen M, Laukli E (1994) Multifrequency tympanometry. Preliminary experiences with a commercially available middle-ear analyser. Audiology 33:245-253

5. Moore GF et al (2002) Revision tympanoplasty utilising fossa triangularis cartilage. Laryngoscope 112:1543-1554

6. Velepic M, Starcevic R, Ticac R, Kujundzic M, Velepic M (2012) Cartilage palisade tympanoplasty in children and adults: long term results. Int J Paediatric Otorhinolaryngology 76:663-666 
7. Gierek T, Slaska-Kasper A, Majzel K, Klimczak-Golab L (2004) Results of myringoplasty and type I tympanoplasty with the use of fascia, cartilage and perichondrium grafts. Otolaryngol Pol 58:529-533

8. Glasscock ME, House WF (1968) Homograft reconstruction of the ear. A preliminary report. Laryngoscope 78:1219-1225

9. Dornhoffer J (2003) Cartilage tympanoplasty: indications, techniques, and outcomes in a 1,000-patient series. Laryngoscope 113:1844-1856

10. Caylan R, Titiz A, Falcioni M, De Donato G, Russo A, Taibah A et al (1998) Myringoplasty in children: factors in influencing surgical outcome. Otolaryngol Head Neck Surg 118:709-713

11. Salén B (1964) Myringoplasty using septum cartilage. Acta Otolaryngol Suppl 188:82-91

12. Jansen C (1963) Cartilage tympanoplasty. Laryngoscope 73:1288-1302

13. Adkins WY (1990) Composite autograft for tympanoplasty and tympmastoidd surgery. Laryngoscope 100:244-276

14. Poe DS, Gadre AK (1993) Cartilage tympanoplasty for management of retraction pocket sand cholesteatomass. Laryngoscope 103:614-618

15. Gerber MJ, Mason JC, Lambert PR (2000) Hearing results afterprimaryy cartilage tympanoplasty. Laryngoscope 110:1994-1999

16. Karaman E, Duman C, Işıldak H, Enver Ö (2010) Composite cartilage island grafts in type I tympanoplasty: audiological and otological outcomes. J Craniofac Surg 21:37-39

17. Khan MM, Parab SR (2011) Primary cartilage tympanoplasty: our technique and results. Am J Otolaryngol 32:381-387

18. Boone RT, Gardner EK, Dornhoffer J (2004) The success of cartilage graft in revision tympanoplasty without mastoidectomy. Otol Neurotol 25:678-681

\section{Publisher's Note}

Springer Nature remains neutral with regard to jurisdictional claims in published maps and institutional affiliations.

\section{Submit your manuscript to a SpringerOpen ${ }^{\circ}$ journal and benefit from:}

- Convenient online submission

- Rigorous peer review

- Open access: articles freely available online

- High visibility within the field

- Retaining the copyright to your article

Submit your next manuscript at $\boldsymbol{\nabla}$ springeropen.com 